Hydraulic Engineering Repository

Ein Service der Bundesanstalt für Wasserbau

Zevenbergen, Lyle W.

Comparison of the HEC-18, Melville and Sheppard Pier Scour Equations

Verfügbar unter / Available at:

https://hdl.handle.net/20.500.11970/100254

Vorgeschlagene Zitierweise / Suggested citation:

Zevenbergen, Lyle W. (2010): Comparison of the HEC-18, Melville and Sheppard Pier Scour Equations. In: Burns, Susan E.; Bhatia, Shobha K.; Avila, Catherine M. C.; Hunt, Beatrice E. (Hg.): Proceedings 5th International Conference on Scour and Erosion (ICSE-5), November 7-10, 2010, San Francisco, USA. Reston, Va.: American Society of Civil Engineers. S. 1074-1081. 


\title{
Comparison of the HEC-18, Melville and Sheppard Pier Scour Equations
}

\author{
L.W. Zevenbergen ${ }^{1}$, M.ASCE
}

${ }^{1}$ Senior Hydraulic Engineer, Ayres Associates Inc, 3665 JFK Parkway, Building 2, Suite 200, Fort Collins, CO 80525; PH (970) 223.5556; FAX (970) 223.5578; email: lylez@,ayresassociates.com

\begin{abstract}
Three frequently cited pier scour equations are the HEC-18 (also known as the CSU equation), Melville and Sheppard equations. Direct comparisons of these three equations were conducted for a wide range of realistic hydraulic, pier size and sediment size conditions. Each equation was applied following the procedure prescribed in the applicable manuals. The range of conditions was intended to cover the vast majority of pier scour calculations that would be encountered during scour evaluations. More than 2500 scour calculations were performed for each equation. This exercise was not meant to determine which equation is "right," "wrong," "better," or "worse." It was meant to give insight into the similarities and differences between the results of the equations and to address the topic of the perceived degree of conservativeness in pier scour calculations.

Each of the equations predicts much greater or less scour than the other two depending on the specific input data. The Melville equation tends to produce the greatest scour and the Sheppard equation tends to produce the least. On average, the Melville equation computes scour over 30 percent more than the Sheppard equation and the HEC-18 equation computes scour approximately 15 percent more than the Sheppard equation. The majority of results were within $+/-30$ percent for HEC-18 compared with Sheppard.

One difference between the equations is that Sheppard includes a threshold velocity condition for pier scour, so it can predict zero scour for some conditions. Neither the HEC-18 nor Melville equations include this threshold velocity, so some amount of pier scour is always computed for these equations.
\end{abstract}

\section{INTRODUCTION}

The three pier scour equations that were compared are the HEC-18 (Richardson and Davis 2001), Melville (Melville and Coleman, 2000) and Sheppard (Florida DOT, 2005) equations. The three equations were applied to the data contained in Table 1. The data are intended to represent the majority of conditions for pier scour experienced in practice. All combinations of six flow velocities, eight flow depths, eight pier widths and seven bed material (D50) sizes were used for total of 2688 pier scour calculations for each equation. No result was discarded. Pier shape was considered to be circular for each of the calculations because this shape is the basis for the vast majority of pier scour research and because adjustments for computed scour depth for various shapes tend to be similar between the equations. 
The data in Table 1 result in the following range of hydraulic parameters and length scales:

Froude Number 0.03-1.53

Pier width/D50: $15.24-45,720$

Pier width/Flow Depth: 0.025-10.0

$\mathrm{Vc}(\mathrm{ft} / \mathrm{s})(\mathrm{HEC}-18): 0.36-2.54 \mathrm{~m} / \mathrm{s}(1.17-8.33 \mathrm{ft} / \mathrm{s})$

$\mathrm{Vc}(\mathrm{ft} / \mathrm{s})($ Melville): $0.32-2.76 \mathrm{~m} / \mathrm{s}(1.06-9.06 \mathrm{ft} / \mathrm{s})$

$\mathrm{Vc}(\mathrm{ft} / \mathrm{s})$ (Sheppard): $0.32-2.69 \mathrm{~m} / \mathrm{s}(1.04-8.84 \mathrm{ft} / \mathrm{s})$

V/Vc (HEC-18) 0.12-12.87

V/Vc (Melville) 0.11-14.09

V/Vc (Sheppard) 0.11-14.49

Note that each method includes a different equation for computing the critical velocity (incipient motion velocity) for particle movement.

Table 1. Data used for Pier Scour Comparisons.

\begin{tabular}{|c|c|c|c|c|c|c|}
\hline \multicolumn{2}{|c|}{ Flow Velocity } & \multicolumn{2}{|c|}{ Flow Depth } & \multicolumn{2}{c|}{ Pier Width } & D50 \\
\hline $\mathrm{ft} / \mathrm{s}$ & $\mathrm{m} / \mathrm{s}$ & $\mathrm{ft}$ & $\mathrm{m}$ & $\mathrm{ft}$ & $\mathrm{m}$ & $\mathrm{mm}$ \\
\hline 1 & 0.3 & 3 & 0.9 & 1 & 0.3 & 0.2 \\
\hline 2 & 0.6 & 6 & 1.8 & 2.5 & 0.8 & 0.5 \\
\hline 5 & 1.5 & 9 & 2.7 & 5 & 1.5 & 1 \\
\hline 7 & 2.1 & 12 & 3.7 & 7.5 & 2.3 & 2 \\
\hline 11 & 3.4 & 16 & 4.9 & 10 & 3.0 & 5 \\
\hline 15 & 4.6 & 20 & 6.1 & 15 & 4.6 & 10 \\
\hline & & 30 & 9.1 & 20 & 6.1 & 20 \\
\hline & & 40 & 12.2 & 30 & 9.1 & \\
\hline
\end{tabular}

Each of the three pier scour equations was applied as recommended in the appropriate scour reference. The HEC-18 equation (also known as the CSU equation) was applied based on the information contained in HEC-18 with the following 5 assumptions. (1) The bed coefficient, K3, was set to 1.1 for all calculations, (2) wide pier adjustment, Kw, was used when applicable, (3) pier scour was limited to 2.4 times the pier width for Froude number $<=0.8$, (4) pier scour was limited to 3.0 times the pier width for Froude numbers $>0.8,(6)$ the armoring coefficient, K4, was not applied (therefore set to 1.0) because a uniform bed material size is used and because the equation for this factor has proven to be unreliable.

In general, each of the equations is empirical to the extent they are based on laboratory data. The HEC-18 equation is considered to be the most empirical because it is a regression fit of lab data with several "correction" factors that have been added over time. The Melville and Sheppard equations are similar in concept because they are based on a more complete set of factors from dimensional analysis (velocity/critical velocity, flow depth/pier width, pier width/sediment size). In comparison, the HEC-18 equation does not include critical velocity or sediment size, but does include Froude number, a variable that is difficult to justify.

The following sections compare the scour estimates produced by the three equations. For the range of data included in Table 1, the HEC-18 and Sheppard 
equations produce similar scour estimates with the HEC0-18 equation tending to produce more scour than Sheppard. The Melville and Sheppard results are the most dissimilar, with Melville consistently producing more scour than Sheppard. Each of the equations can produce more or less scour than the other two, depending on the particular situation.

\section{COMPARISON OF MELVILLE AND HEC-18 EQUATIONS}

Figure 1 shows the results of the 2688 scour calculation for the Melville and HEC-18 equations for the data included in Table 1 . The three red lines in the figure are a line of perfect agreement (1:1) and lines depicting plus and minus 30 percent. A linear regression line (thin black line) indicates that Melville is, on average, 28 percent greater than HEC-18. Approximately 1400 of the points (52 percent) are within plus or minus 30 percent, leaving a significant number of points that are well outside this range. There are instances when either equation produces over five times the scour of the other equation. The Melville equation tends to predict much greater scour when the scour amounts are large and less scour when the scour amounts are small. For this exercise, the HEC-18 equation never computes less than one foot of scour though the Melville equation does.

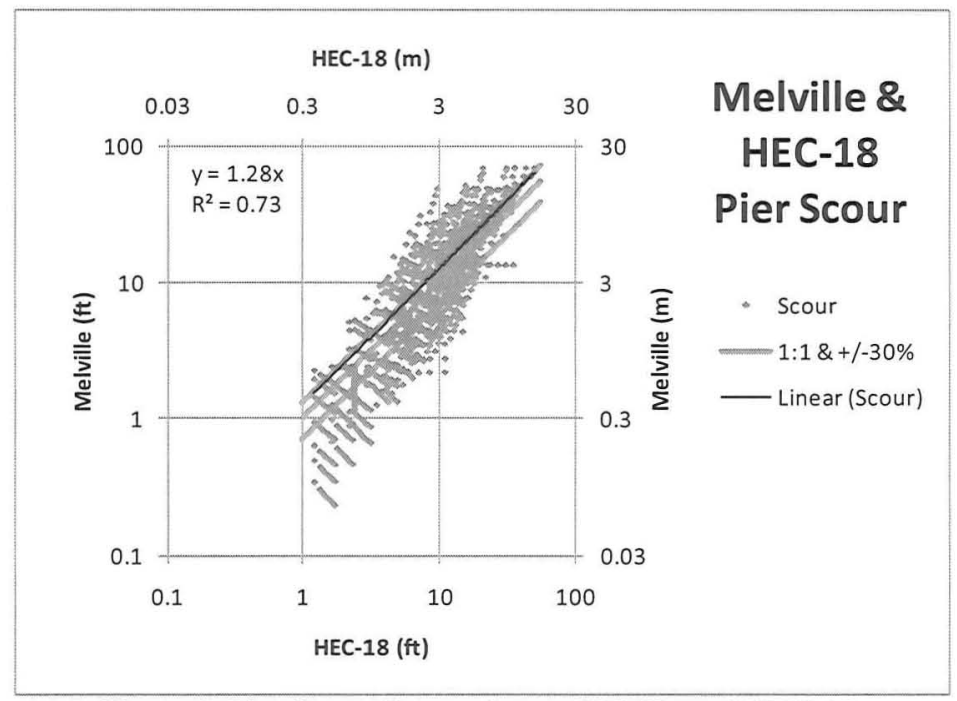

Figure 1. Pier Scour Comparison - Melville and HEC-18.

\section{COMPARISON OF SHEPPARD AND HEC-18 EQUATIONS}

As shown in Figure 2, the Sheppard and HEC-18 equations produce much more consistent results. Nearly 1900 of the data points $(70 \%)$ are within plus or minus 30 percent. On average the Sheppard equation results in 15 percent less scour 
than the HEC-18 equation. There are two other significant features of this plot. First, there are several instances when the Sheppard equation computes no scour when the HEC-18 equation computes significant scour. This is because the Sheppard equation computes no scour when the velocity is less than $0.47 \mathrm{Vc}$. Note that for purposes of graphical representation, the Sheppard equation is assigned a scour of $0.03 \mathrm{~m}(0.1$ feet) when it computes no scour. The other significant feature is similar. There are "stringers" of data where the Sheppard equation produces scour well below the minus 30 percent line. These data are for velocities very close to $0.47 \mathrm{Vc}$. As noted, the HEC-18 equation does not include a V/Vc factor, nor does it include a "no scour" condition.

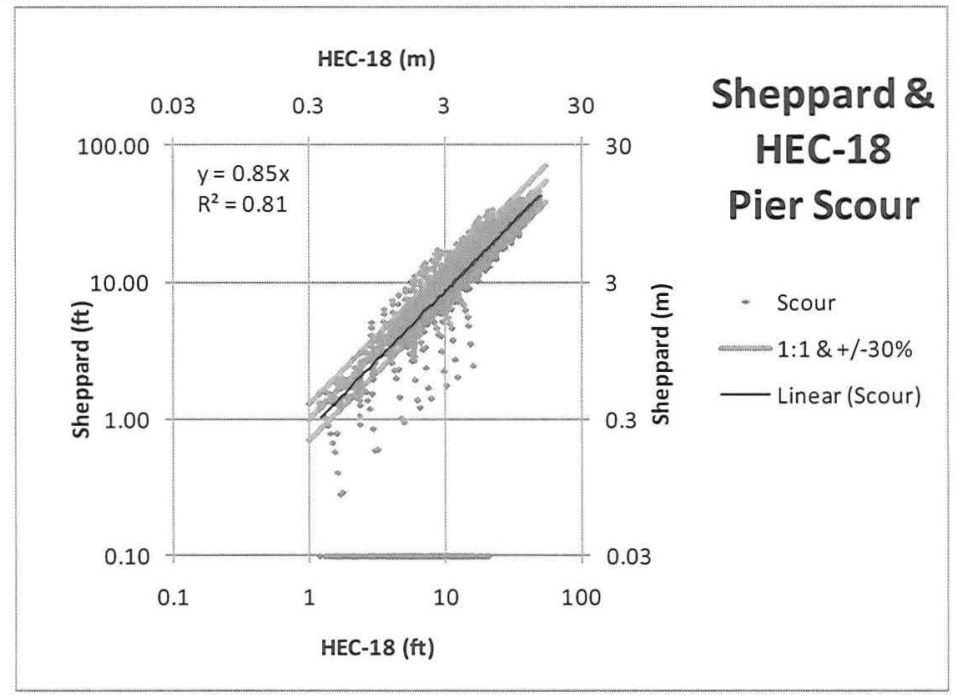

Figure 2. Pier Scour Comparison - Sheppard and HEC-18.

\section{COMPARISON OF MELVILLE AND SHEPPARD EQUATIONS}

Considering the results of the previous comparisons it is not surprising that, on average, the Melville equation computes significantly greater scour than the Sheppard equation. As shown in Figure 3, only about 900 of the Melville equations points (37 percent) are within plus or minus 30 percent of the Sheppard equation points, and very few are within the zero to minus 30 percent area. This plot demonstrates that the Melville equation also does not include a zero scour condition. Therefore, like HEC-18, it computes significant scour for conditions when the Sheppard equation results in no scour. Also similar to HEC-18, there are "stringers" of data for conditions close to $0.47 \mathrm{Vc}$ when the Melville equations computes significant scour and the Sheppard equation produces much less. This plot also shows that the Sheppard and Melville equations are correlated, at least much more so than the Melville and HEC-18 equations, but the Melville equation consistently produces more scour. 


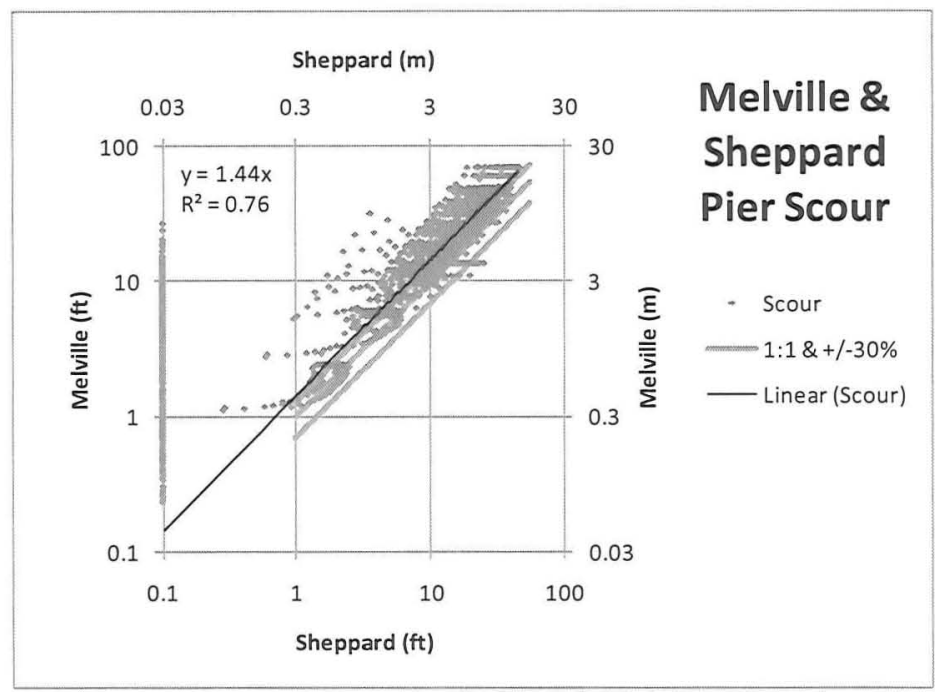

Figure 3. Pier Scour Comparison - Melville and Sheppard.

\section{CRITICAL VELOCITY COMPARIONS}

Each of the three approaches includes a method for computing critical velocity (incipient motion velocity). The Melville and Sheppard methods are very similar, with the only differences being the values of coefficients. The Melville equation results in slightly greater values of $\mathrm{Vc}$ than the Sheppard equation. The HEC-18 method is much simpler. Each method depends on particle size and flow depth. Figure 4 shows that the HEC-18 approach computes greater values of $\mathrm{Vc}$ for smaller particle sizes and smaller values of $\mathrm{Vc}$ for larger particles. The computations were performed for particle sizes and flow depths shown in Table 1.

For the initiation of particle movement at a pier (Vcp), the Sheppard approach uses a value of $0.47 \mathrm{Vc}$. For velocities less than Vcp, the Sheppard approach results in no pier scour. The Melville scour manual indicates that Vcp may be as low as $0.3 \mathrm{Vc}$, but does not include this as a lower limit in practice. In the Melville method pier scour is initiated for any non-zero velocity. The HEC-18 manual does include an equation for Vcp, but does not use it as the beginning of pier scour. Rather, Vcp is used as part of the "out of favor" armoring factor, but it is not the Vcp calculation that is in question. One difference between the HEC-18 and the other two equations for Vcp is that the HEC-18 equation includes pier size, so a larger pier starts to scour at lower velocities than smaller piers.

Figure 5, 6, and 7 are repeats of Figures 1,2, and 3, except that $0.3 \mathrm{Vc}$ is used as Vcp (and the pier scour threshold) for the Melville equation and the HEC-18 equation for $\mathrm{Vcp}$ is the used as a pier scour threshold. Figure 5, which compares Melville and HEC-18, now looks much more like the Sheppard-Melville comparison (Figure 3). 


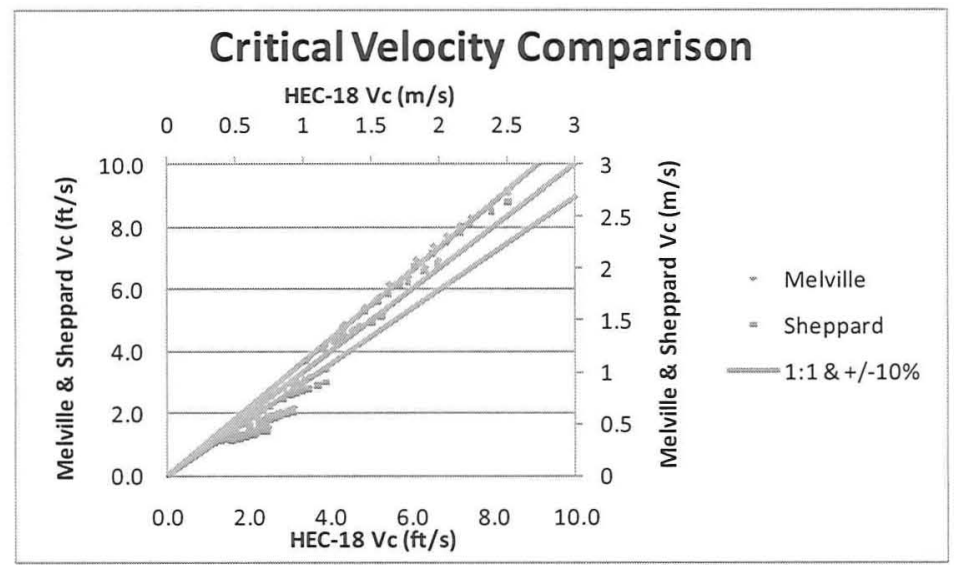

Figure 4. Critical Velocity Comparisons.

This is because many of the small scour results became no scour for both equations (shown as $0.03,0.03 \mathrm{~m}$ ) or no scour just for the HEC-18 equation. Figure 6, which compares Sheppard and HEC-18, has not change drastically from Figure 2, expect that the "stringers" are mostly gone. There are conditions when this approach results in either equation computing no scour and the other equation producing significant scour. There is very little change between Figure 3 and Figure 7, the MelvilleSheppard comparisons. This is because some of the points that Sheppard computed no scour also became no scour for the Melville equation.

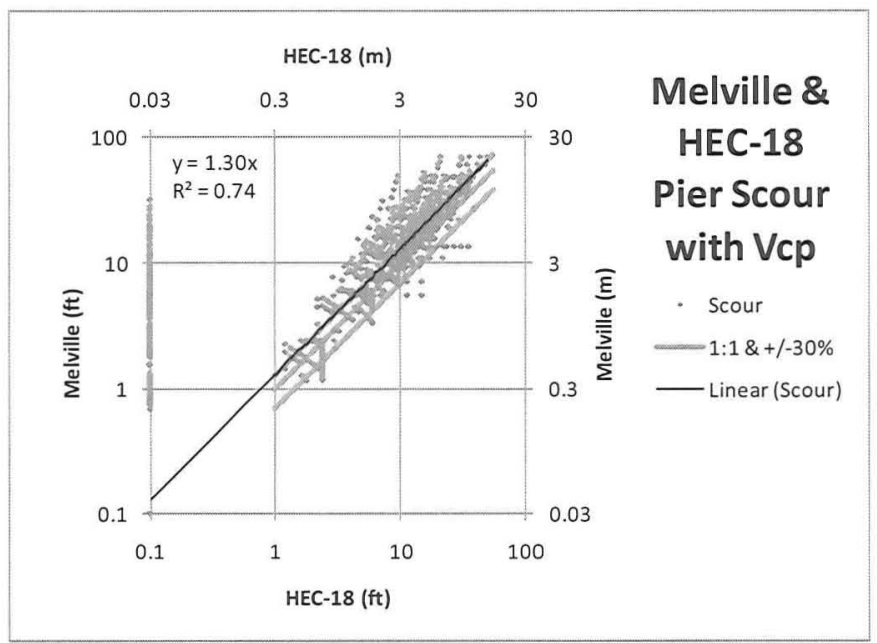

Figure 5. Pier Scour Comparison including Pier Vep - Melville and HEC-18. 


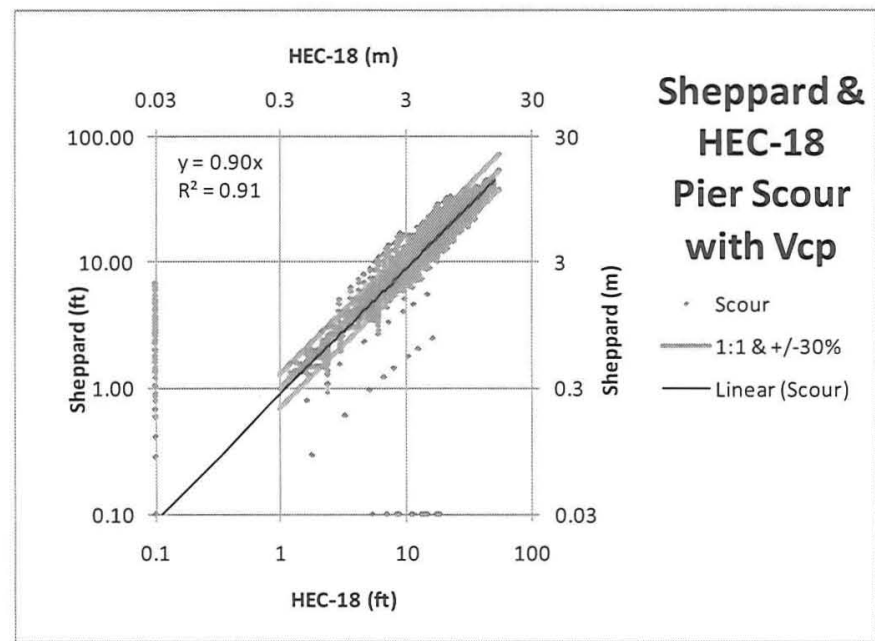

Figure 6. Pier Scour Comparison including Pier Vep - Sheppard and HEC-18.

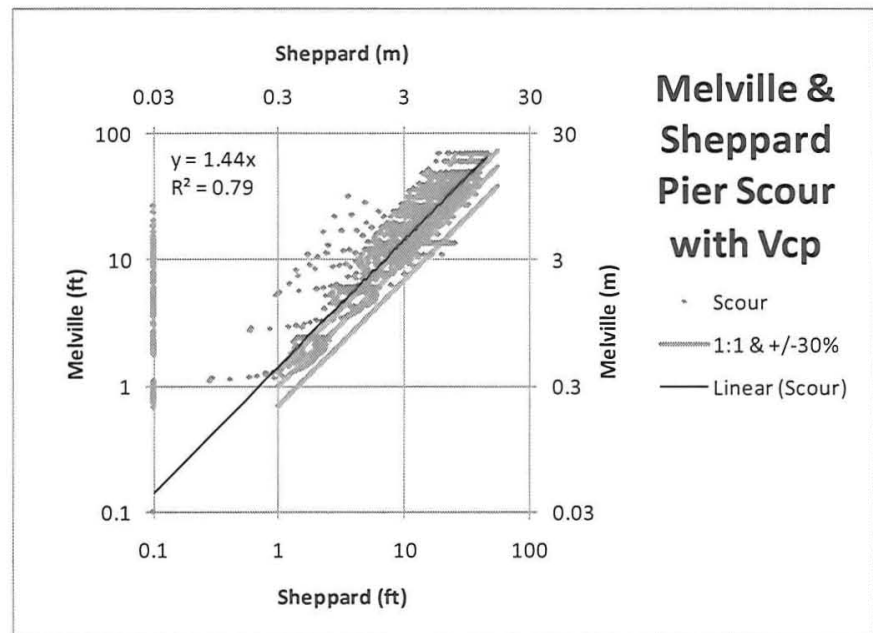

Figure 7. Pier Scour Comparison including Pier Vep - Melville and Sheppard.

\section{CONCLUSIONS}

There is a strong perception that the HEC-18 equation consistently and considerably overestimates pier scour. Although this may be true, the results of the HEC-18 equations are consistently less than the Melville equation and, on average, only 15 percent more than the Sheppard equation. Therefore, if the HEC-18 equation 
is grossly over-conservative, then each of these equations must include a considerable degree of conservativeness. This is a good thing. If, on average, pier scour amounts were calculated as they would occur, then around have of the calculations would underestimate scour. For design purposes there needs to be a level of conservatism.

This paper does not argue that pier scour estimation should not or could not be improved or that one equation is better than the others. Many engineers believe that the Sheppard equation is more accurate and gives more realistic predictions of scour for design purposes. If it is, then there are cases when using the HEC-18 may underpredict scour. None of the scour equations is perfect and all probably over-predict frequently and under-predict occasionally. The biggest differences between the equations appear to be for flow conditions well below incipient motion (below around $0.6 \mathrm{Vc}$ ). However, this is a relatively rare design condition. It may be appealing to improve, or at least gain some consistency between, the approaches for addressing the "no pier scour" condition, but it will not impact the vast majority of bridge design conditions. For flow velocities approaching and above live-bed conditions, the results are fairly consistent. The biggest difference between the equations appears to be a stronger inclination to use envelope curves by Melville.

This paper only addresses direct comparisons of the equations. Although it is also appealing to compare the equations to field data, the limitations of field data must also be recognized. These limitations include accuracy of the scour measurement, accuracy of the hydraulic variables, whether the scour has reached equilibrium conditions, bed material variability, and material erodibility (rock, clay, fines, etc.).

\section{REFERENCES}

Florida Department of Transportation (2005). "Bridge Scour Manual," Florida Department of Transportation, 129 pages.

Melville, B.W. and Coleman, S.A. (2000). "Bridge Scour," Water Resources Publications, 576 pages.

Richardson, E.V. and Davis, S.R. (2001). "Evaluating Scour at Bridges," Fourth Edition, Hydraulic Engineering Circular No. 18, FHWA-NHI-01-001, Washington, D.C. 